\title{
Biological Characteristics and Clinical Significance of ITGB1 and RHOC in Patients With Recurrent Colorectal Cancer
}

\author{
YE JIN HA ${ }^{1,2}$, KA HEE TAK $^{1,2}$, SEON-KYU KIM ${ }^{3}$, CHAN WOOK KIM ${ }^{1,2}$, JONG LYUL LEE $^{1,2}$, \\ SEON AE ROH ${ }^{1,2}$, DONG-HYUNG CHO ${ }^{4}$, SEON-YOUNG KIM ${ }^{3}$, YONG SUNG KIM ${ }^{3}$ and JIN CHEON KIM ${ }^{1,2}$ \\ ${ }^{1}$ Department of Surgery, University of Ulsan College of Medicine, Seoul, Republic of Korea; \\ ${ }^{2}$ Asan Institute for Life Sciences, Asan Medical Center, Seoul, Republic of Korea; \\ ${ }^{3}$ Medical Genomics Research Center, Korea Research Institute of Bioscience \& Biotechnology, Daejeon, Republic of Korea; \\ ${ }^{4}$ School of Life Science, Kyungpook National University, Daegu, Republic of Korea
}

\begin{abstract}
Background/Aim: Colorectal cancer $(C R C)$ is the leading cause of cancer mortality worldwide. Its poor prognosis can be ascribed primarily to high recurrence rates. Accordingly, the aim of this study was to identify novel prognostic biomarkers and therapeutic targets for management of CRC. Materials and Methods: To develop prognostic biomarkers, we performed RNA-seq analysis and real-time RT-PCR in primary cancer tissues with or without systemic recurrence. To characterize the molecular functions of the encoded proteins, CRC cells underexpressing or overexpressing the candidate genes were established and appropriate cell-based assays were applied. Results: ITGBI and RHOC $m R N A$ levels were up-regulated in the recurrence group of CRC patients. Overexpression of ITGBI or RHOC stimulated CRC cell proliferation, invasion and migration, whereas the opposite effects were observed in cells underexpressing either protein. Five-year recurrence-free survival rates were significantly higher in the ITGB1- and RHOC-underexpression groups than those in the overexpression. Conclusion: ITGBI and RHOC are potential predictors of recurrence and therapeutic targets for CRC, possibly predicting a high-risk group of stage II patients. Colorectal cancer (CRC) is a leading cause of morbidity and mortality worldwide $(1,2)$. Currently, the accurate
\end{abstract}

Correspondence to: Dr. Jin Cheon Kim, Department of Surgery, University of Ulsan College of Medicine, 88, Olympic-ro 43-gil, Songpa-gu, Seoul 05505, Republic of Korea. Tel: +82 230103489, Fax: +82 24749027, e-mail: jckim@amc.seoul.kr; ORCID: 00000003-4823-8619; Dr. Yong Sung Kim, Genome Editing Research Center, Korea Research Institute of Bioscience and Biotechnology, 52 Eoeun-dong Yuseong-gu, Daejeon 34141, Republic of Korea. Tel: +82 428798110, Fax: +82 428798119, e-mail: yongsung@kribb.re.kr; ORCID: 0000-0001-7113-272X

Key Words: Colorectal cancer, ITGB1, RHOC, recurrence, predictive marker. identification of CRC patients at high risk of recurrence remains a major clinical challenge. A variety of clinical and biological factors have been proposed as predictive prognostic markers for CRC (3), but the precise molecular mechanisms underlying the development and progression of this disease remain to be elucidated. The identification of novel molecular markers for the prediction of recurrence risk for CRC could help improve strategies for individualized patient management. However, very few surrogate predictive markers, based on distinct molecular phenotypes, related to CRC recurrence are known. Additionally, although remarkable progress has been made in determining the prognosis of patients with CRC, it remains unclear how to identify the subset of stage II and III patients (classified by the American Joint Committee on Cancer, 8th ver., 2017) who are at high risk of experiencing tumor recurrence, resulting in mortality (4-6).

In this study, we sought to prospectively evaluate the prognostic and predictive value of tissue RNA in patients with CRC. To this end, RNA-seq on tumor tissue samples, followed by a reverse-transcription polymerase chain reaction (RT-PCR) assay was performed. Using gain- and loss-offunction approaches, the effects of differentially expressed proteins on cell proliferation, invasion, and migration, as well as the epithelial-mesenchymal transition (EMT), were investigated in vitro. Finally, we attempted to identify biomarkers that constitute a prognostic signature for patients with stage II and III disease in terms of systemic recurrence.

\section{Materials and Methods}

Patient enrolment and sample acquisition. A previous study by our group identified 117 recurrence-associated genes based on the cutoff of $\log 2$ transcript count per million (TPM) of mean values in an initial population of 130 patients (no recurrence $=72$; recurrence $=58$ ) (7). In this study, mRNA expression was analyzed in an additional CRC 75 cases (Table I) using real time RT-PCR in tumor tissues. All samples were collected at Asan Medical Center (AMC, Seoul, 
Table I. Validation cohort for real time RT-PCR.

\begin{tabular}{|c|c|c|c|}
\hline Parameters $^{\mathrm{a}}$ & $\begin{array}{c}\text { Systemic recurrence - } \\
(\mathrm{n}=42)\end{array}$ & $\begin{array}{c}\text { Systemic recurrence }+ \\
(\mathrm{n}=33)\end{array}$ & $p$-Value \\
\hline Gender, male/female & $29 / 13$ & $27 / 6$ & 0.21 \\
\hline Age, years & $61 \pm 7$ & $58 \pm 9$ & 0.36 \\
\hline Pathological stage ${ }^{\mathrm{c}}, \mathrm{I} / \mathrm{II} / \mathrm{III} / \mathrm{IV}$ & $3 / 24 / 15 / 0$ & $0 / 10 / 23 / 0$ & 0.01 \\
\hline \multicolumn{4}{|l|}{ Primary tumor } \\
\hline Location ${ }^{\mathrm{d}}$, right/left/rectum & $11 / 21 / 10$ & $7 / 8 / 18$ & 0.02 \\
\hline Growth, expanding/infiltrative & $34 / 8$ & $26 / 7$ & 0.82 \\
\hline Differentiation, W/M/P/mucinous & $2 / 35 / 3 / 2$ & $0 / 26 / 3 / 2$ & 0.43 \\
\hline Lymphovascular invasion, no/yes & $36 / 6$ & $18 / 15$ & 0.003 \\
\hline Perineural invasion, no/yes & $36 / 6$ & $18 / 15$ & 0.003 \\
\hline
\end{tabular}

W/M/P: Well, moderately, or poorly differentiated. aContinuous values are means \pm standard deviation; values in parentheses are percentages; ${ }^{b} \mathrm{All}$ parameters were compared using Pearson's $\chi^{2}$ and unpaired t-tests; 'Pathological cancer staging according to the American Joint Committee on Cancer (Eighth ed., 2017); ${ }^{\mathrm{d}}$ Right, cecum-transverse colon; left, descending colon-sigmoid colon.

Table II. Primers for real-time RT-PCR and siRNA sequences for the two selected candidate genes.

\begin{tabular}{lcc}
\hline Genes & Sequence & RefSeq \\
\hline ITGB1 & Forward: GGATTCTCCAGAAGGTGGTTTCG & NM_033667 \\
RHOC & Reverse: TGCCACCAAGTTCCCATCTCC & Norward: AAGACGAGCACACCAGGAGAGA \\
& Reverse: TTGGCTGAGCACTCAAGGTAGC & NM1042679 \\
\hline
\end{tabular}

Republic of Korea) and stored in liquid nitrogen prior to use. Written consent was obtained from all patients, and the study protocol was approved by the Institutional Review Board of Asan Medical Center (registration number: 2018-0087).

Transcriptome profiling and selection of two genes for predicting $C R C$ recurrence. RNA extraction, RNA-seq experiments, and data processing were carried out as previously described (7). Recurrenceassociated genes were identified based on a correlation test between $\mathrm{CRC}$ recurrence and gene expression levels using data from the AMC cohort (point-biserial correlation test, $p<0.001,|r|>0.30$ ). To explore the biological pathways that are active during CRC recurrence, gene set enrichment analysis was performed on the recurrence-associated genes, and genes in significantly activated or inhibited pathways were aggregated. Ultimately, two genes (ITGBI and $R H O C$ ) were chosen based on their prognostic relevance for $\mathrm{CRC}$ recurrence and expression levels. The RNA-seq dataset is available in the NCBI Gene Expression Omnibus repository under accession numbers GSE50760 and GSE107422.

Real-time RT-PCR. Total RNA was extracted from patient samples and cell lines using the TRIzol Reagent (Invitrogen, Carlsbad, CA, USA). cDNA for real-time RT-PCR was synthesized from total RNA using random primers and SuperScript II RT (Thermo Fisher Scientific, Waltham, MA, USA). Real-time RT-PCR was performed on a Roche LightCycler 96 (Roche, Mannheim, Germany) with SYBR Green I Master Mix (Roche). Primers used to amplify target genes are listed in Table II. PCR conditions were as follows: pre- incubation at $95^{\circ} \mathrm{C}$ for $10 \mathrm{~min} ; 45$ cycles of amplification $\left(95^{\circ} \mathrm{C}\right.$ for $10 \mathrm{sec}, 60^{\circ} \mathrm{C}$ for $10 \mathrm{sec}$, and $72^{\circ} \mathrm{C}$ for $\left.10 \mathrm{sec}\right)$; melting $\left(95^{\circ} \mathrm{C}, 65^{\circ} \mathrm{C}\right.$, and $97^{\circ} \mathrm{C}$ for $10 \mathrm{sec}$ each); and cooling at $37^{\circ} \mathrm{C}$ for $30 \mathrm{sec}$. The gene encoding glyceraldehyde 3 -phosphate dehydrogenase $(G A P D H)$ was used as an internal control.

Cell culture and gene transfection. Ten CRC cell lines (DLD1, HCT15, HCT116, HT29, LS174T, LoVo, RKO, SW480, SW620, and WiDr) were obtained from ATCC (Manassas, VA, USA). All cell lines were confirmed to be free of mycoplasma and authenticated using purified DNAs on a 3130x1 Genetic analyzer with the GeneMapper software ver. 5 (Cosmogenetech, Seoul, Republic of Korea). Cells were cultured in RPMI-1640 supplemented with $10 \%(\mathrm{v} / \mathrm{v})$ fetal bovine serum and $1 \%(\mathrm{w} / \mathrm{v})$ penicillin and streptomycin. cDNAs of two genes [integrin subunit beta 1 (ITGB1) and Ras homolog family member C (RHOC)] were purchased from OriGene (Rockville, MD, USA). Typical tags include the amino acid sequence "DYKDDDDK" (DDK-tag). Cells transfected with pCMV6-entry vector were used as negative controls. Transient transfection was performed in cancer cells using Lipofectamine 2000 (Invitrogen), and stably expressing cells were selected with G418 for 10 days; at least two clones were selected for each cell line. For knockdown, siRNAs against ITGB1 (8) and RHOC (9) (BIONEER, Daejeon, Korea) were transfected into cells using the RNAiMax transfection reagent (Invitrogen). siRNA sequences are provided in Table III. Negative control siRNA was also acquired from BIONEER. Expression of the two proteins was confirmed by western blotting. 
Table III. siRNA sequences for the two selected candidate genes.

\begin{tabular}{lc}
\hline Genes & siRNA sequence 5'-3' \\
\hline$I T G B 1$ & Sense: CUGUUCUUUGGAUACUAGU \\
& Antisense: ACUAGUAUCCAAAGAACAG \\
RHOC & Sense: GUGCCUUUGGCUACCUUGA \\
& Antisense: UCAAGGUAGCCAAAGGCAC \\
\hline
\end{tabular}

Western blotting. Protein concentration in extracts from cultured cells were quantified using Bradford solution (Bio-Rad, Hercules, CA, USA). Proteins were resolved by SDS-PAGE, and then transferred to polyvinylidene difluoride membrane (Millipore, Billerica, MA, USA). The membranes were incubated consecutively with primary and secondary antibodies. Specific complexes were detected using the SuperSignal West Pico kit (Thermo Fisher Scientific, Rockford, IL, USA). The following antibodies were used: anti-ITGB1, anti-RHOC, anti-E-Cadherin, anti-N-Cadherin, and anti-Vimentin from Abcam (Cambridge, UK), and anti- $\beta$-Actin, anti-mouse $\mathrm{IgG}$, and anti-rabbit IgG from Bethyl Laboratories (Montgomery, TX, USA).

Cell proliferation, migration, and invasion assays. To assess proliferation, CRC cells were seeded onto 96-well plates. Fold changes in the number of cells were measured every day for 5 days using the CCK-8 cell proliferation assay kit (CCK-8; Dojindo, Kumamoto, Japan); absorbance at $450 \mathrm{~nm}$ was monitored on a microtiter plate reader (Tecan, Melbourne, Australia). For invasion and migration assays, CRC cells $\left(2 \times 10^{5}\right.$ cells/well $)$ were seeded in the upper chambers of 24-well culture plates on Biocoat ${ }^{\mathrm{TM}}$ Matrigel invasion chambers and Transwell chambers (BD Biosciences, San Jose, CA, USA), respectively. 3T3-fibroblast-conditioned medium was placed in the lower chamber as a chemoattractant. After incubation at $37^{\circ} \mathrm{C}$ for $24 \mathrm{~h}$, cells on the lower surface of the membrane were stained with $0.1 \%$ crystal violet and counted in three different fields under a light microscope $(\times 100)$. All assays were performed in triplicate.

Gelatin zymography. Matrix metalloprotease (MMP)-2 and MMP-9 activities in culture media were assessed by gelatin zymography. Conditioned media were concentrated using Amicon Ultra-4 Centrifugal Filter (Millipore, Billerica, MA, USA) and mixed with sample buffer and subjected to SDS-PAGE on a $10 \%$ gel containing $0.1 \%$ gelatin (Invitrogen), which was incorporated as a substrate for gelatinolytic proteases under non-reducing conditions. Gels were incubated at $37^{\circ} \mathrm{C}$ for $16 \mathrm{~h}$ in fresh developing buffer, and then stained with $0.5 \%$ Coomassie brilliant blue R-250 (Bio-Rad). Areas of enzyme activity appeared as white bands against a dark blue background White bands were quantified using a densitometer (Bio-Rad).

Statistical analysis. Demographic and biological features of patients with and without systemic recurrence were compared using Fisher's exact test or unpaired Student's $t$-test. Differential mRNA expression and cellular activity were compared between two groups using the Mann-Whitney $U$-test. In the control cohorts, it was not possible to perform adequate survival analysis due to heterogeneity of tumor stages and treatment modalities; instead, the public
Table IV. Baseline characteristics of patients with CRC in the CIT cohort.

\begin{tabular}{lc}
\hline Parameters & No. of patients $(\%)(\mathrm{n}=566)$ \\
\hline Gender, male/female & $310 / 256(54.8 / 45.2)$ \\
Median age, range, y & $68,22-97$ \\
Location, colon/rectum & $566 / 0(100 / 0)$ \\
AJCC stage, I/II/III/IV & $37 / 264 / 205 / 60(6.5 / 46.7 / 36.2 / 10.6)$ \\
Adjuvant chemotherapy, & $233 / 316 / 17(41.2 / 55.8 / 3)$ \\
yes/no/not available & 177 \\
No. of events & 48 \\
Median disease-free & \\
survival, months & \\
\hline
\end{tabular}

CIT: Cartes d'Identité des Tumeurs; AJCC: American Joint Committee on Cancer.

database of the French Ligue Nationale Contre le Cancer (CIT cohort, GSE39582, n=566) was used for this purpose (Table IV). To calculate the best cutoff for expression of each gene, a receiver operating characteristics analysis was performed in which the optimal cutoff value was determined as the expression level with highest sensitivity and specificity. Recurrence-free survival (RFS) was compared using the Kaplan-Meier method with the log-rank test. Statistical significance was assigned when $p<0.05$. All calculations were performed using the SPSS software (ver. 21; SPSS Inc., Chicago, IL, USA).

\section{Results}

Identification of genes associated with recurrence. In a previous study, we found that ITGBI and $R H O C$ were overexpressed in primary cancer tissues with recurrence by RNA-seq analysis [manuscript in press]. In this study, higher mRNA levels of ITGBI $(p=0.006)$ and RHOC $(p=0.026)$ were confirmed in another cohort of $75 \mathrm{CRC}$ patients with $(n=42)$ or without $(n=33)$ recurrence (Figure 1$)$.

Overexpression of ITGBI and RHOC promotes proliferation, migration, and invasion of CRC cells. To investigate the biological implications of altered expression of the two proteins in CRC cells, western blotting was performed to assess the expression levels of ITGB1 and RHOC in a panel of colon cancer cell lines (Figure 2). For overexpression studies, HCT15 and SW620 cell lines were selected for ITGB1, and HCT15 and LoVo cell lines for RHOC. For knockdown studies, HCT116 and RKO cell lines were selected for ITGB1, and HCT116 and RKO cell lines were selected for RHOC. The proliferative activities of the two molecules were measured in CRC cells overexpressing ITGB1 (Figure 3a) or RHOC (Figure 4a); two clones were assessed for each candidate. In ITGB1-overexpressing HCT15 and SW620 cells, proliferation increased significantly from day 3 to day 5 relative to control cells 

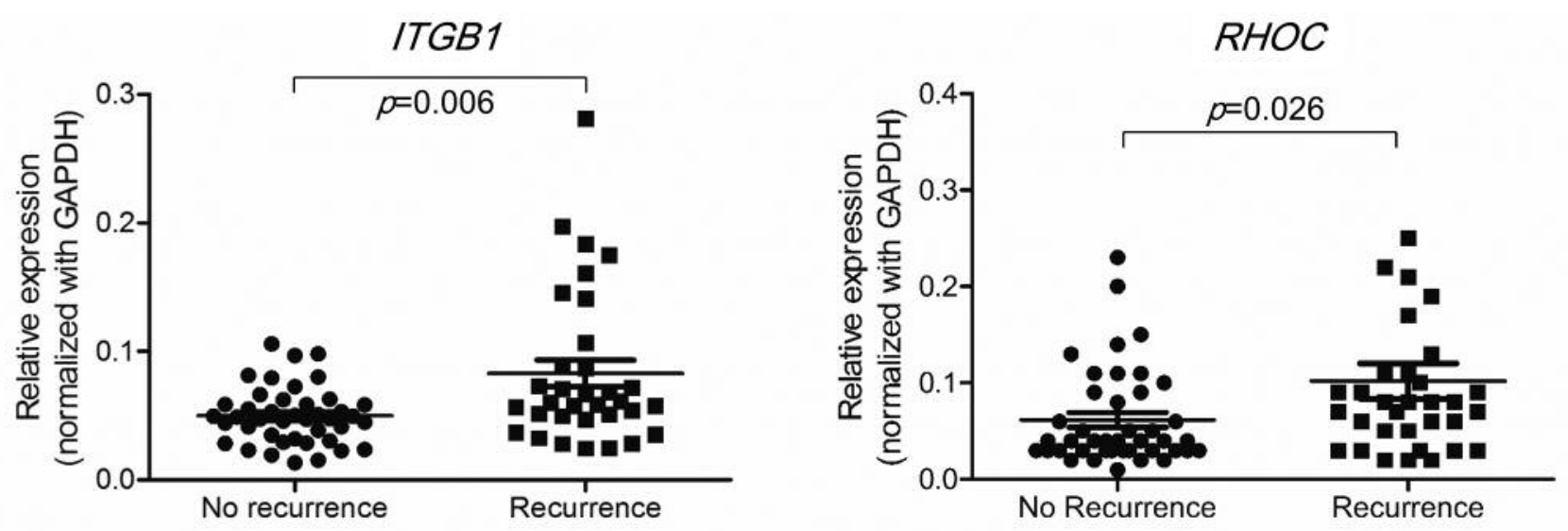

Figure 1. mRNA levels of ITGB1 and RHOC in a total of 75 patients with no recurrence $(n=42)$ or recurrence $(n=33)$. CRC tissues in the clinical validation cohort were analyzed using real-time RT-PCR. Data were obtained from three independent experiments performed in triplicate. Error bars represent standard error. ${ }^{*} p<0.05$ between no recurrence and recurrence.

(Figure 3b). Similarly, RHOC-overexpressing HCT15 cells and LoVo cells proliferated more rapidly from day 4 to day 5 (Figure 4b). In invasion and migration assays, ITGB1overexpressing HCT15 and SW620 cells exhibited significantly elevated migration (Figure 3c) and invasion (Figure 3d) relative to control cells, as did RHOCoverexpressing HCT15 and LoVo cells (migration, Figure 4c; invasion, Figure $4 d)(p<0.05)$.

Down-regulation of ITGBI or RHOC inhibits proliferation, migration, and invasion of CRC cells. To confirm the roles of ITGB1 and RHOC in cell proliferation, motility, and invasion, ITGB1 (Figure 5a) or RHOC (Figure 6a) were knocked down in CRC cells. Cell proliferation was significantly suppressed in ITGB 1 (Figure 5b) and RHOC (Figure 6b) knockdown cells relative to control cells. Invasion and migration assays revealed that knockdown of either protein inhibited migration (Figure 5c and 6c) and invasion (Figure 5d and 6d). Collectively, these results indicate that ITGB1 and RHOC promote CRC recurrence by stimulating cell growth, invasion, and migration.

ITGB1 and RHOC affect the activities of MMP-2 and MMP9. Then, we performed gelatin zymography assays to examine the effect of ITGB1 and RHOC on the activities of the matrix metalloproteases MMP-2 and MMP-9, which are indispensable for CRC metastasis. The activities of both enzymes were significantly elevated in cells overexpressing ITGB1 (Figure 7a) or RHOC (Figure 8a), but reduced in cells transfected with siRNA-ITGB1 (Figure 7b) or siRNARHOC (Figure 8b).

ITGBI and RHOC affect the expression of E-Cadherin, $N$ Cadherin, and Vimentin. Then, western blotting was

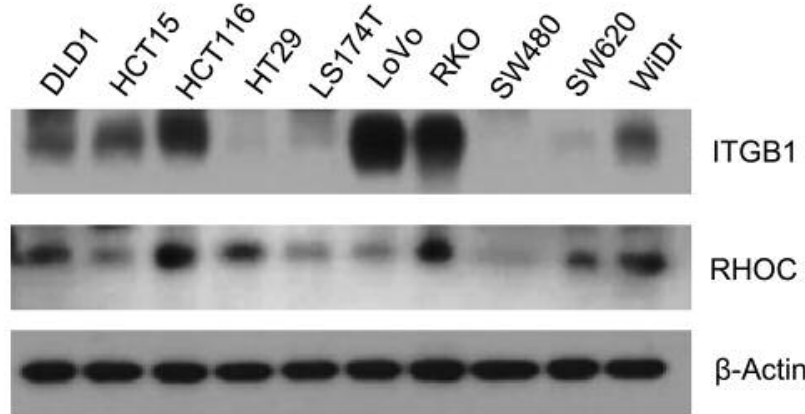

Figure 2. ITGB1 and RHOC expression status in CRC cell lines.

performed to analyze the expression of selected epithelialmesenchymal transition (EMT) proteins associated with CRC invasion and metastasis. EMT is characterized by loss of epithelial cell junction proteins, such as E-Cadherin, concomitant with gain of mesenchymal markers such as Vimentin. Over the course of EMT, cells lose their epithelial characteristics and acquire mesenchymal properties, including motile and invasive features. Reduced E-Cadherin expression contributes to tumor cell migration and invasion and is inversely correlated with tumor stage. N-Cadherin is involved in EMT, as well as in metastasis of cancer cells. In cells overexpressing ITGB1 or RHOC, expression of the epithelial marker E-Cadherin was reduced, whereas the mesenchymal markers $\mathrm{N}$-Cadherin and Vimentin were clearly up-regulated (Figure 7c and 8c). The opposite effects were observed in ITGB1- or RHOC-knockdown cells (Figure $7 \mathrm{~d}$ and $8 \mathrm{~d})$.

ITGBI and RHOC mRNA expression predicts disease-free survival. Finally, we examined RFS rates in the CIT cohort 
a

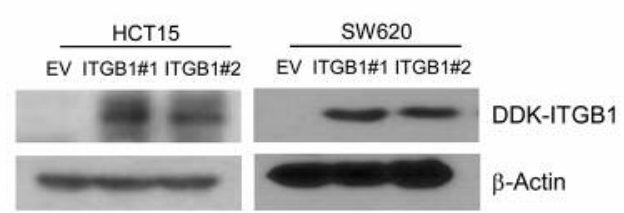

C

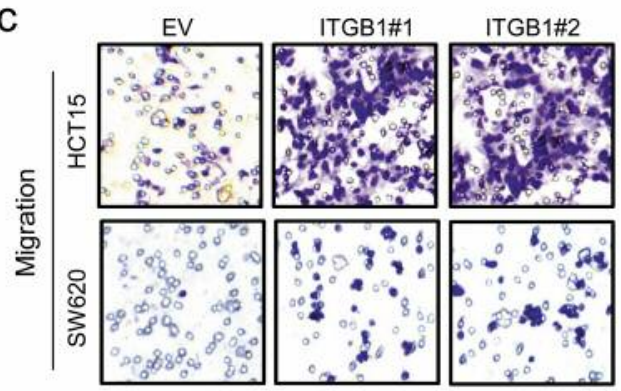

d

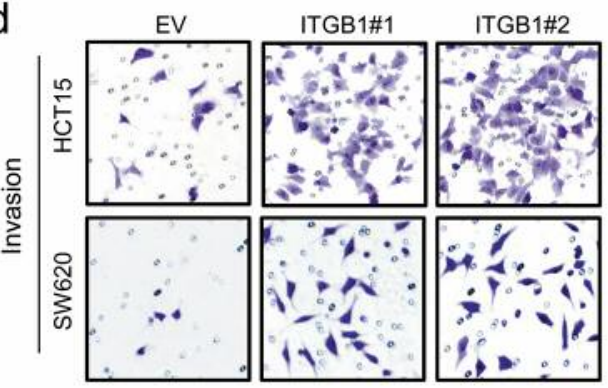

b
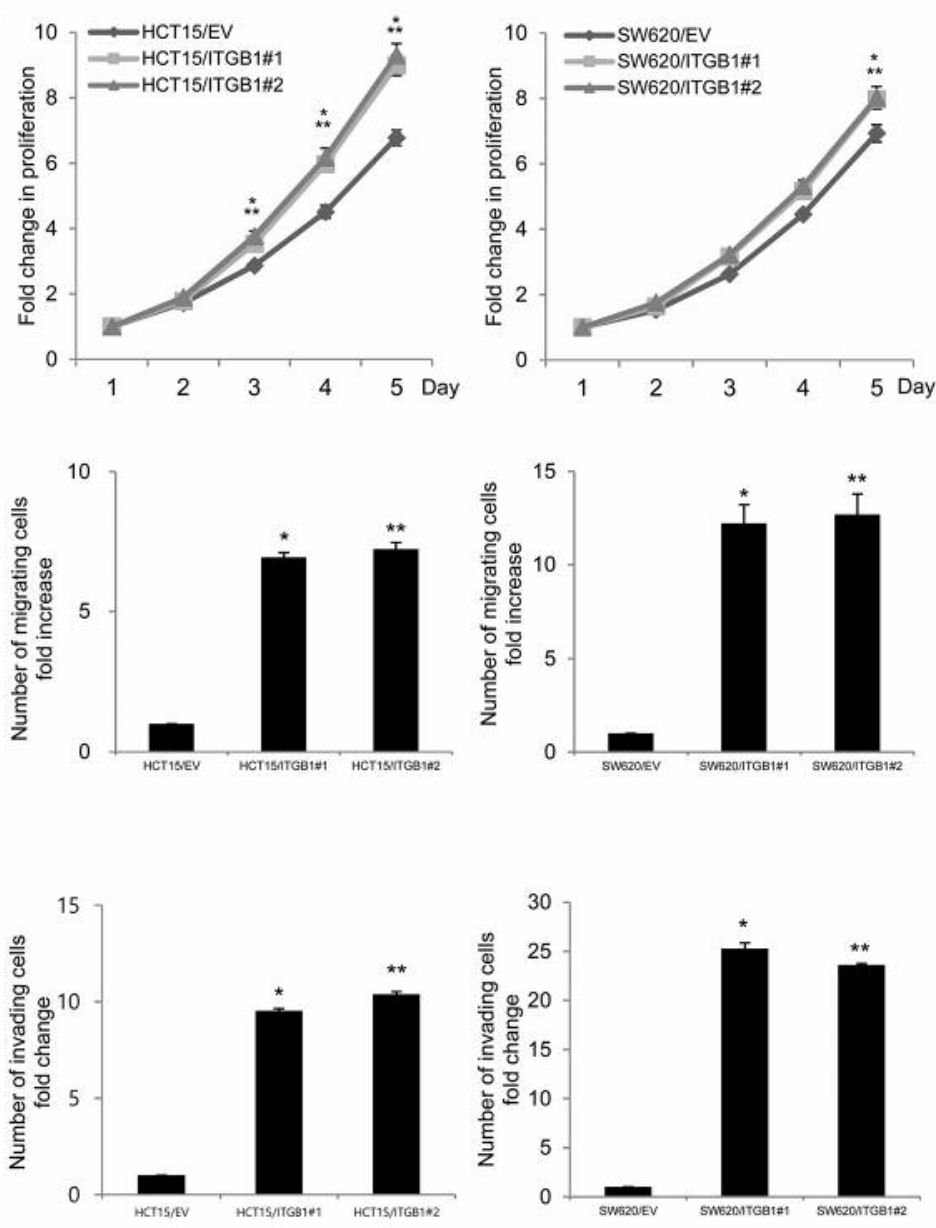

Figure 3. Overexpression of ITGB1 increases proliferative, invasive, and migrative activities in CRC cell lines. Western blotting with anti-DDK antibody confirmed ITGB1 overexpression in two clones each of HCT15 and SW620 (a) transfected with ITGB1, but not in cells transfected with empty vector $(E V)$. Cell proliferation ability was evaluated by growth curve analysis over 5 days (b). Migration (c) and invasion (d) were detected after incubation at $37^{\circ} \mathrm{C}$ for $24 \mathrm{~h}$. Data were obtained from three independent experiments performed in triplicate. Error bars represent the standard error. ${ }^{*} p<0.05$ between ITGB1 clone 1(\#1) and EV; **p<0.05 between ITGB1 clone 2(\#2) and EV.

to assess the usefulness of ITGBI and RHOC mRNA expression for predicting recurrence (Figure 9). Five-year RFS rates were significantly higher in the RHOCunderexpression group than in the $R H O C$-overexpression group ( $p=0.003$ ), and survival outcomes according to tumor stage confirmed significant differences between the two groups ( $p=0.02$ for stage II patients; $p=0.006$ for stage III patients). Five-year RFS rates were also significantly higher in the ITGBl-underexpression group than in the ITGB1-overexpression group, and survival outcomes according to tumor stage showed a significant difference between the two groups in stage III, but only a weak trend in stage II ( $p=0.18$ for stage II patients; $p=0.037$ for stage III patients).

\section{Discussion}

Recurrence is the most life-threatening consequence of CRC because more than three-quarters of cases involving relapse are intractable to curative treatments (10). Accordingly, optimization of primary treatment based on the risk of recurrence represents a more promising strategy than either deliberate post-treatment surveillance or aggressive salvage therapy. Currently, 5-fluorouracil (5FU)-based adjuvant chemotherapy remains the main treatment for stage III CRC patients and some high-risk stage II CRC patients; these regimens improve survival rates by $\sim 20 \%(11,12)$. For stage III patients, 30-40\% of patients do not experience recurrence within 5 years even when left untreated, whereas about $40 \%$ 

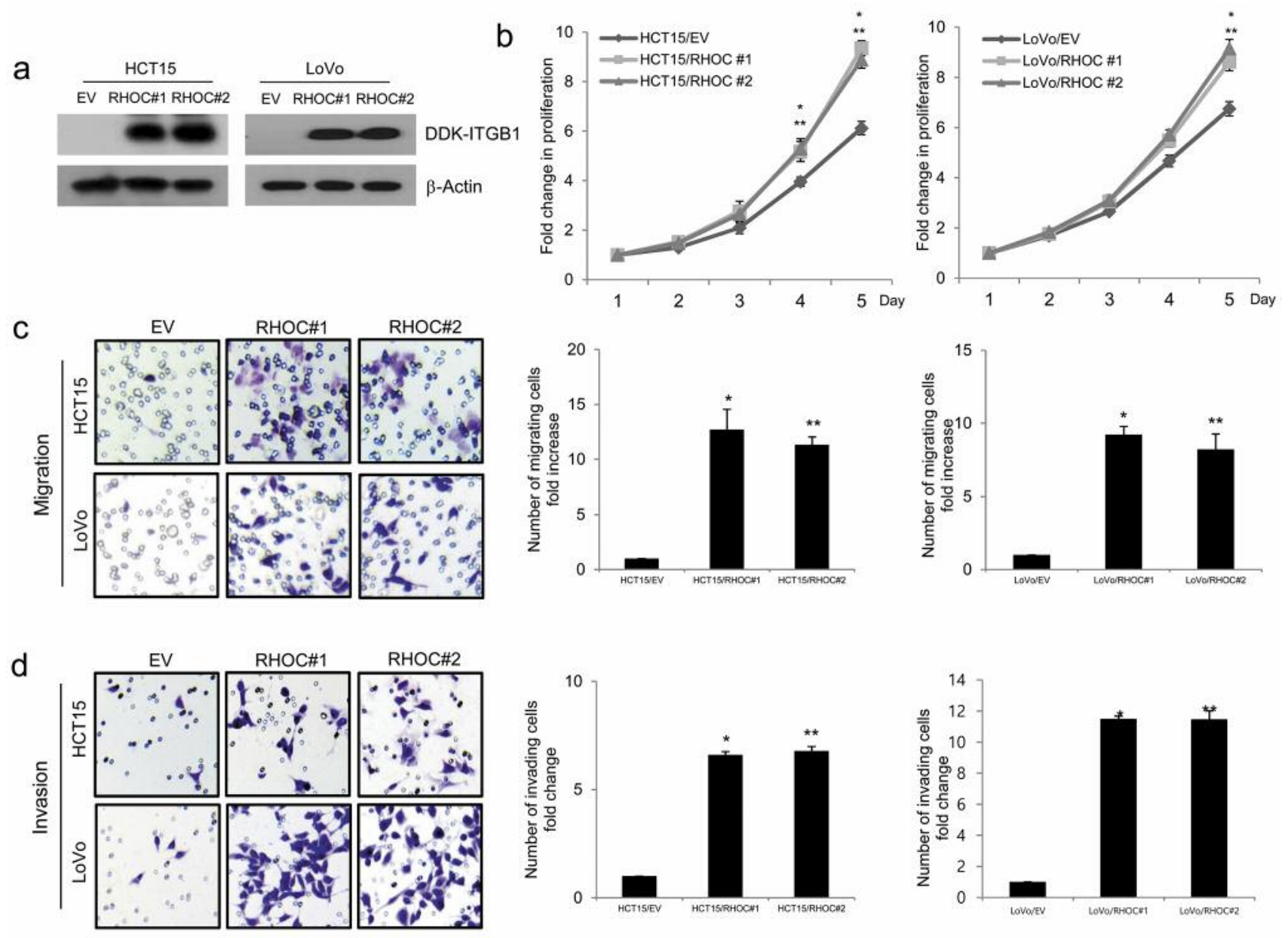

Figure 4. Overexpression of RHOC increases proliferative, invasive, and migrative activities in CRC cell lines. Western blotting with anti-DDK antibody confirmed RHOC overexpression in two clones each of HCT15 and LoVo (a) transfected with RHOC, but not in cells transfected with empty vector $(E V)$. Cell proliferation ability was evaluated by growth curve analysis over 5 days $(b)$. Migration $(c)$ and invasion $(d)$ were detected after incubation at $37^{\circ} \mathrm{C}$ for $24 \mathrm{~h}$. Data were obtained from three independent experiments performed in triplicate. Error bars represent standard error. $* p<0.05$ between RHOC clone 1(\#1) and $E V ; * *<0.05$ between RHOC clone 2(\#2) and EV.

of patients who undergo adjuvant treatment suffer from relapse and eventually die, suggesting that a subset of these patients need more intensive chemotherapy. On the other hand, among stage II patients, only those who present with high-risk clinical features receive adjuvant chemotherapy. Unfortunately, about $20 \%$ of clinically low-risk patients experience tumor recurrence $(13,14)$.

In the present study, patients with high levels of ITGB 1 and RHOC were at significantly higher risk of recurrence than patients with lower levels of these proteins. The use of ITGB 1 and RHOC as molecular markers to predict recurrence may facilitate optimization of primary treatment and improve the overall outcomes of colon cancer patients. We observed a significant increase in ITGBI and RHOC mRNA levels in primary tumor samples from patients with relapse. In our in vitro experiments, overexpression of ITGB 1 and RHOC in CRC cells promoted cell proliferation, invasion, and migration, whereas knockdown had the opposite effects. Together, these findings demonstrate that ITGB1 and RHOC are intimately involved in CRC progression.

Our results show that ITGB1 expression is higher in CRC tumor tissues with systemic recurrence than in those with no recurrence. Thus, high ITGB1 expression in tumor tissues was significantly associated with poor OS in CRC patients, as reported in previous studies (15). Our histological findings also demonstrated that higher ITGB1 expression in CRC tumor tissues was significantly correlated with depth of invasion, lymph node metastasis, and TNM stage. Integrin$\beta 1$ (ITGB1), also known as CD29, is composed of alpha and 
a

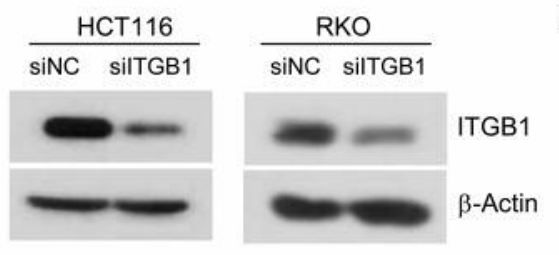

C

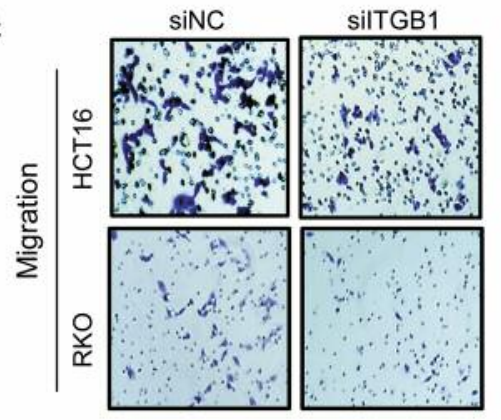

d

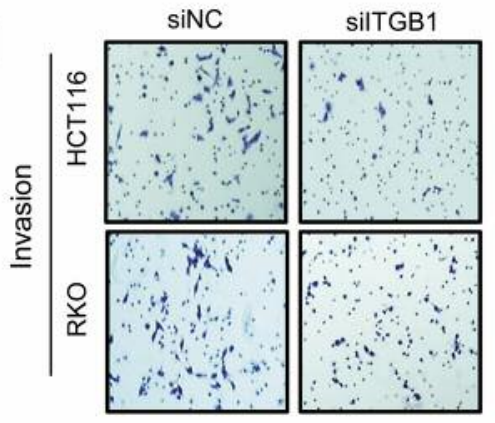

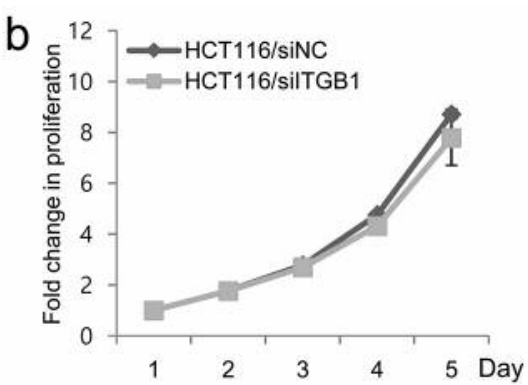
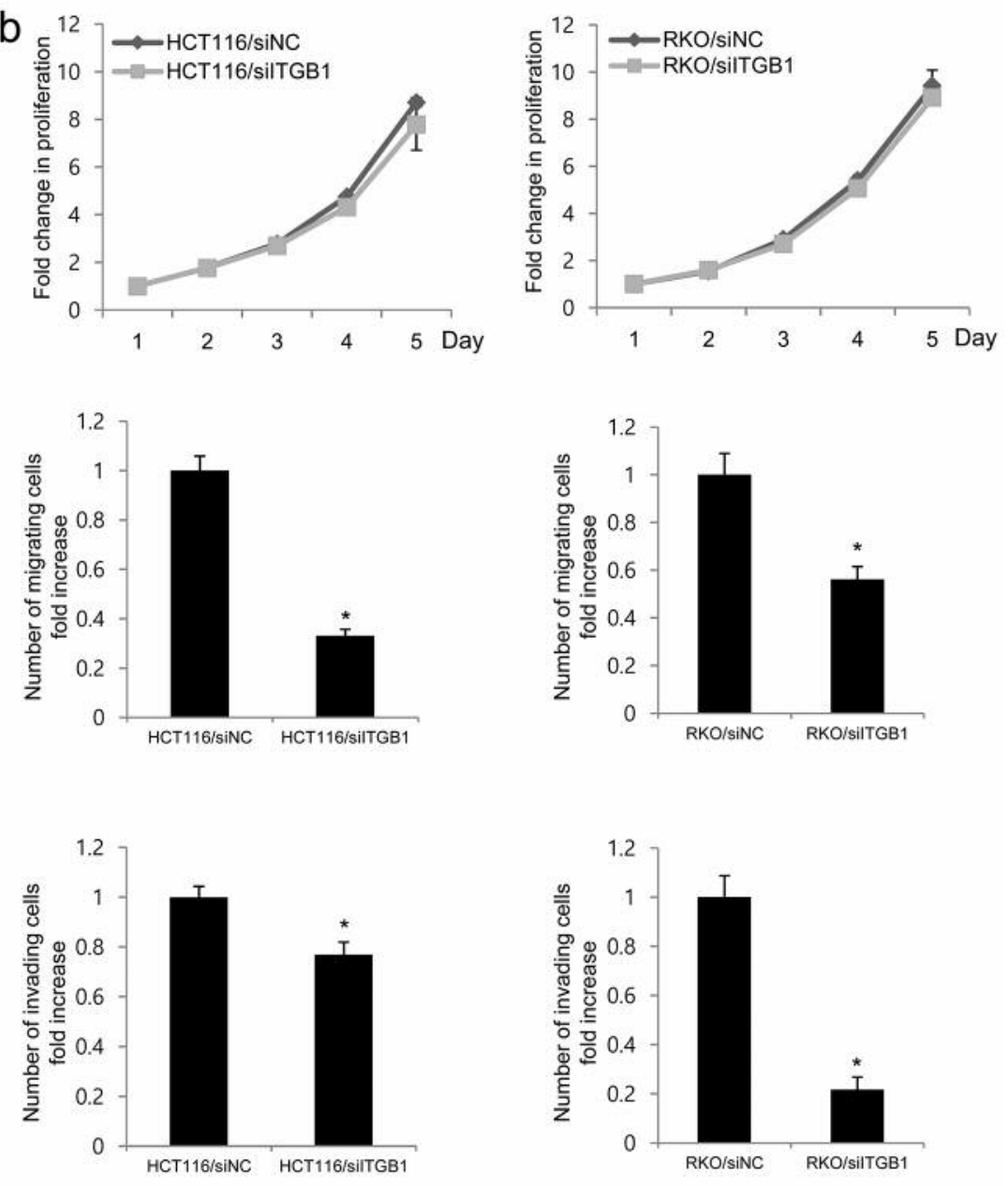

Figure 5. ITGB1 down-regulation decreases the proliferative, invasive, and migrative activities of HCT116 and RKO cells. Western blotting using ITGB1 antibody confirmed ITGB1 knockdown in HCT116 and RKO cells transfected with siITGB1 (a) relative to cells transfected with negative control siRNA (siNC). Cell proliferation ability was evaluated by growth curve analysis over 5 days (b). Migration (c) and invasion $(d)$ were detected after incubation at $37^{\circ} \mathrm{C}$ for $24 \mathrm{~h}$. Data were obtained from three independent experiments performed in triplicate. Error bars represent standard error. ${ }^{*} p<0.05$.

beta transmembrane subunits that form at least 24 distinct heterodimeric receptors (14). ITGB1 is the predominantly expressed integrin in normal and tumor cells, and controls various developmental processes, including angiogenesis, tumor progression, and metastasis (16-20).

We also observed that RHOC expression was higher in early-stage tumor tissues that ultimately advanced to recurrence than in cases that did not recur. High RHOC expression was also correlated with poorer RFS, and served as an independent negative prognostic factor in CRC patients. RHOC, a member of the Rho family, is a GTPbinding protein that hydrolyses GTP to GDP, thereby acting as a signal converter or a molecular switch in signal transduction pathways to produce a variety of biological effects that act on the cytoskeleton or other target proteins $(21,22)$. The most important functions of RHOC are regulation of cell motility and migration via its effects on the actin cytoskeleton and aggregation of actin, integrins, and associated proteins such as fibronectin $(23,24)$.

MMPs are major components of the proteolytic machinery involved in tumor invasion and metastasis $(25,26)$. To further characterize the molecular mechanism underlying ITGB1- and RHOC-mediated invasion and migration of CRC, we examined the effect of ITGB1 and RHOC on the activities of MMP-2, and MMP-9. Overexpression of ITGB1 or RHOC increased the activities of both enzymes, whereas knockdown of either protein had the opposite effects. Because EMT also plays a key role in CRC recurrence (27), the effect of ITGB1 and RHOC 
a

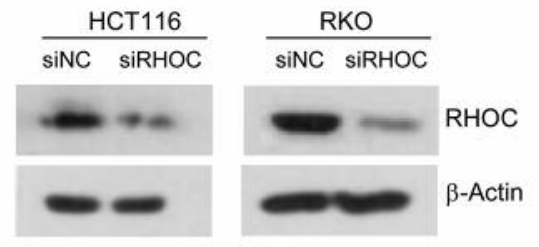

C
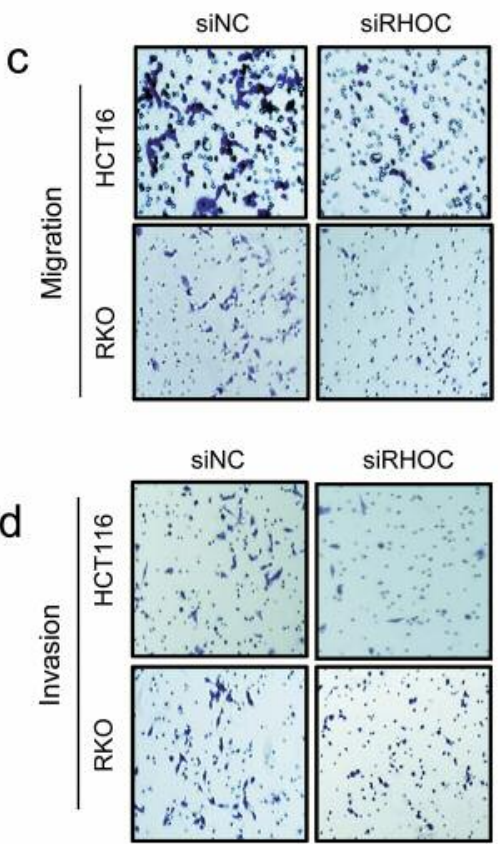

b
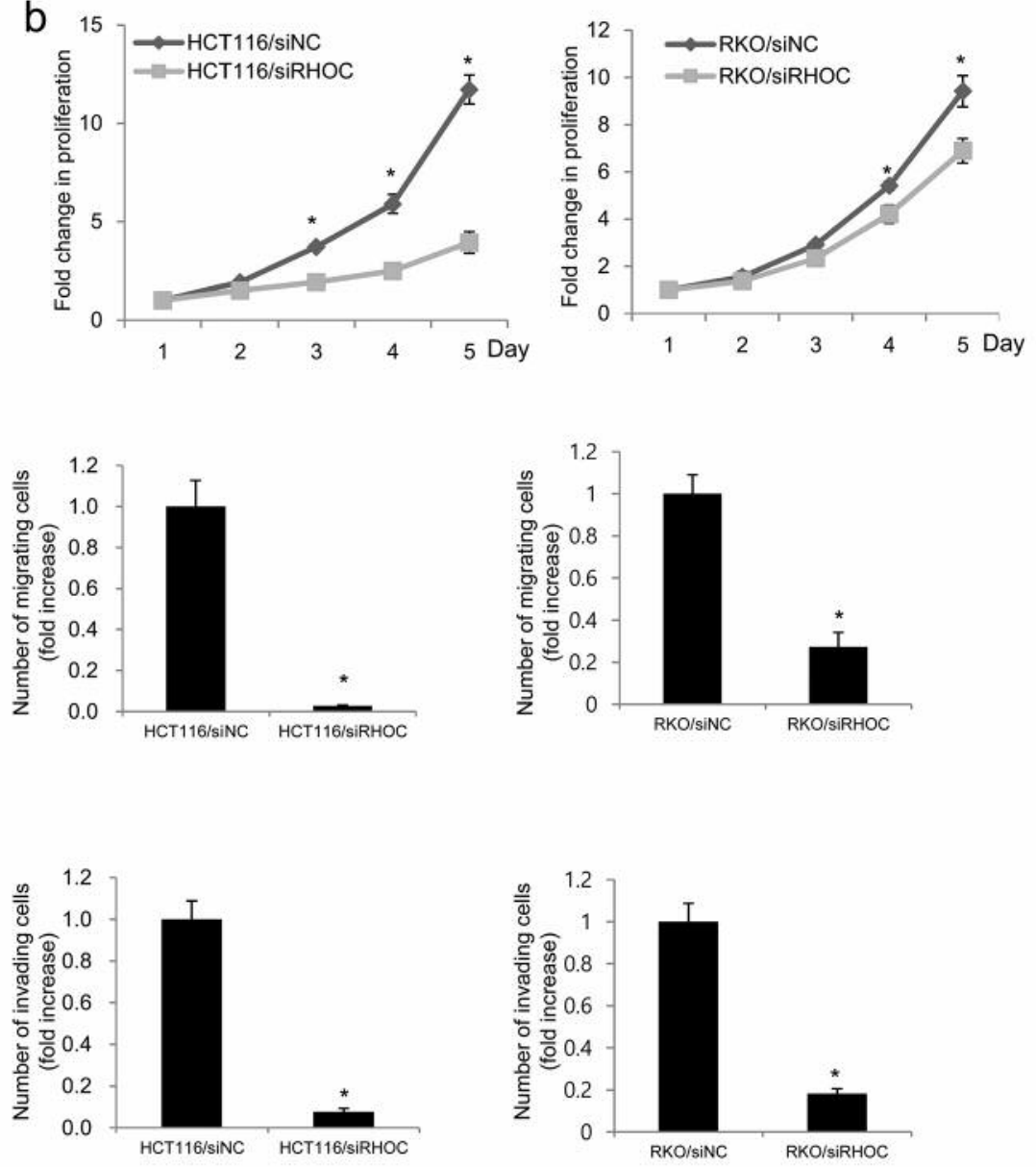

Figure 6. RHOC down-regulation decreases the proliferative, invasive, and migrative activities of HCT116 and RKO cells. Western blotting using RHOC antibody confirmed RHOC knockdown in HCT116 and RKO cells transfected with siRHOC (a) relative to cells transfected with negative control siRNA (siNC). Cell proliferation ability was evaluated by growth curve analysis over 5 days $(b)$. Migration (c) and invasion $(d)$ were detected after incubation at $37^{\circ} \mathrm{C}$ for $24 \mathrm{~h}$. Data were obtained from three independent experiments performed in triplicate. Error bars represent standard error. ${ }^{*} p<0.05$.

on this process in CRC cell lines was investigated. ITGB1 or RHOC increased expression of the mesenchymal markers $\mathrm{N}$-cadherin and vimentin and decreased expression of the epithelial marker E-Cadherin; as with the metalloprotease activity described above, knockdown of the expression of these proteins had the opposite effects. These findings demonstrate that ITGB1 and RHOC alter the expression of various factors related to invasion and migration, thereby facilitating invasive cell proliferation, motility, and metastasis.

Although our findings were derived from objective criteria in terms of initial gene screening and functional assessment, the study had limitations that may affect the overall conclusions. For example, genes that were filtered out by our stringent criteria, which may be associated with recurrence, were excluded without further functional assessment. In addition, survival analysis could not be performed in our cohort because the study population was heterogeneous in terms of recurrence and treatment. Nevertheless, we showed that mRNA levels of ITGBI and RHOC predict stage-specific tumor recurrence in patients with CRC. These results suggest that ITGB1 and RHOC could be clinically useful as diagnostic and predictive biomarkers for risk stratification in CRC patients. Our data provide further support for the importance of tumor dormancy in less advanced CRC, and may help to select subgroups of patients who could benefit from more aggressive treatment strategies, or alternatively from ITGB1- and RHOC-targeted treatments. 

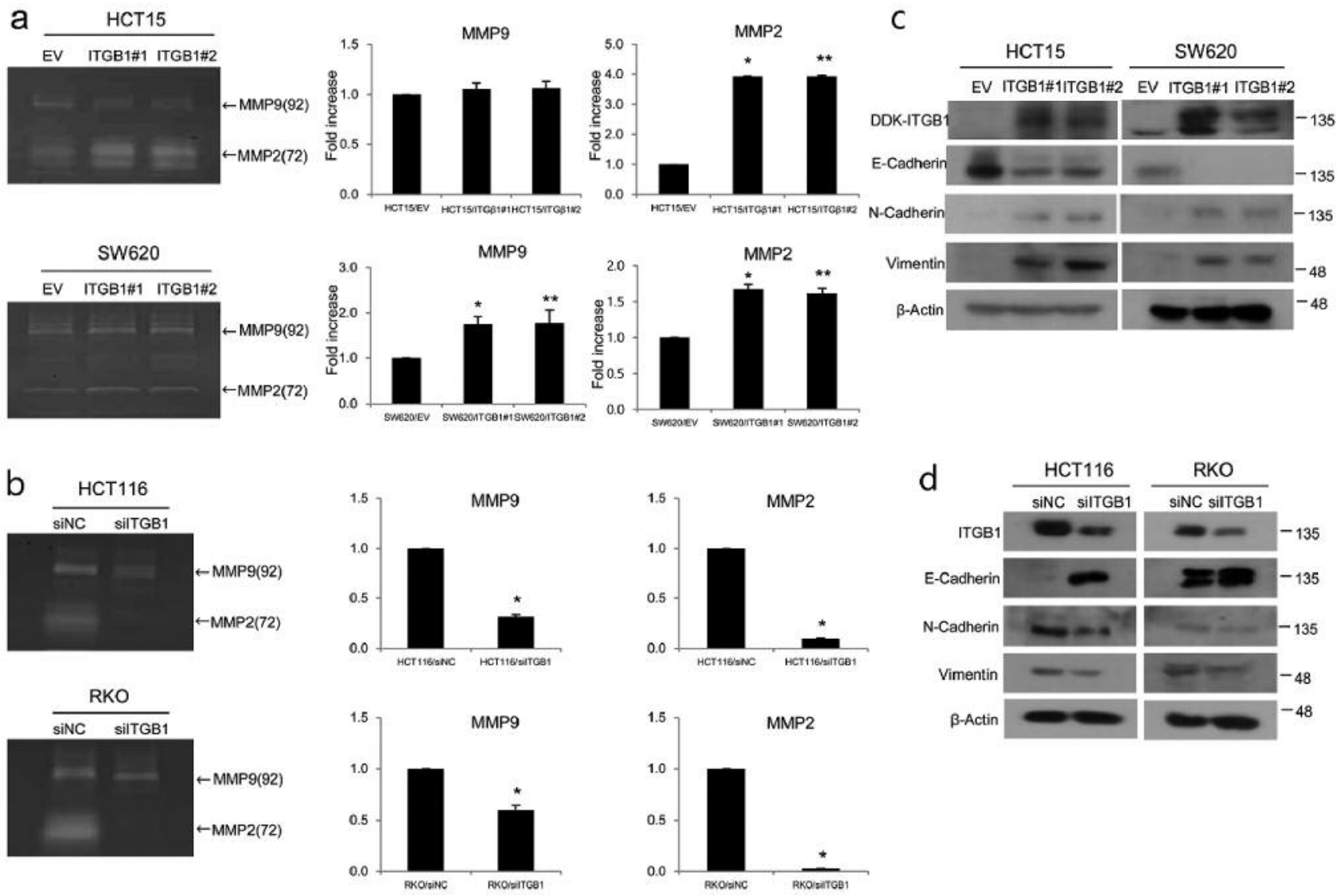

Figure 7. MMP-2 and MMP-9 activities in ITGB1 overexpressing (a) and ITGB1 knockdown (b) CRC cells, as measured by gelatin zymography after serum starvation for $24 \mathrm{~h}$. Immunoblotting of epithelial-mesenchymal transition (EMT) markers in ITGB1 overexpressing (c) and ITGB1 knockdown $(d)$ cells. Data were obtained from three independent experiments performed in triplicate. Error bars represent standard error. ${ }^{*} p<0.05$ between ITGB1 clone 1(\#1) and EV; **p<0.05 between ITGB1 clone 2(\#2) and EV in the overexpression study. EV, Empty vector. *p<0.05 between siRNA and siTGB1 in the knockdown study. siNC: Negative control siRNA.

\section{Conflicts of Interest}

The Authors declare that they have no conflict of interest regarding this study.

\section{Authors' Contributions}

Conceptualization: Jin Cheon Kim, Ye Jin Ha, Seon Ae Roh, Chan Wook Kim, Seon-Kyu Kim, Seon-Young Kim, Dong-Hyung Cho, Yong Sung Kim; Data curation: Ye Jin Ha, Ka Hee Tak, Chan Wook Kim, Jong Lyul Lee, Seon-Kyu Kim, Seon-Young Kim, Dong-Hyung Cho, Jin Cheon Kim; Formal analysis: Ye Jin Ha, Ka Hee Tak, Seon Ae Roh, Chan Wook Kim, Jong Lyul Lee, Seon-Kyu Kim, Seon-Young Kim, Dong-Hyung Cho, Yong Sung Kim, Jin Cheon Kim; Funding acquisition: Jin Cheon Kim; Investigation: Ye Jin Ha, Ka Hee Tak, Chan Wook Kim, Jong Lyul Lee, Seon-Kyu Kim, Seon-Young Kim, Dong-Hyung Cho, Yong Sung Kim, Jin Cheon Kim; Methodology: Ye Jin Ha, Ka Hee Tak, Chan Wook
Kim, Seon-Kyu Kim, Seon-Young Kim, Dong-Hyung Cho, Yong Sung Kim, Jin Cheon Kim; Project administration: Jin Cheon Kim, Ye Jin Ha, Seon-Young Kim, Dong-Hyung Cho, Yong Sung Kim; Resources: Ye Jin Ha, Ka Hee Tak, Chan Wook Kim, Jong Lyul Lee, Seon-Kyu Kim, Seon-Young Kim, Yong Sung Kim; Software: Jin Cheon Kim, Jong Lyul Lee, Seon-Kyu Kim. Supervision: Jin Cheon Kim, Seon-Young Kim, Yong Sung Kim; Validation: Ye Jin Ha, Ka Hee Tak, Chan Wook Kim, Jong Lyul Lee, Seon-Kyu Kim, Seon-Young Kim, Dong-Hyung Cho, Yong Sung Kim, Jin Cheon Kim; Visualization: Ye Jin Ha, Jong Lyul Lee, Seon-Young Kim, Dong-Hyung Cho, Jin Cheon Kim; Writing - original draft: Ye Jin Ha, Seon-Kyu Kim, Jin Cheon Kim; Writing - review \& editing: Ye Jin Ha, Yong Sung Kim, Jin Cheon Kim.

\section{Acknowledgements}

This work was supported, in part, by a Grant to J.C. Kim from the Korea Research Foundation (2016R1E1A1A02919844), Ministry of Science and ICT, Republic of Korea. 

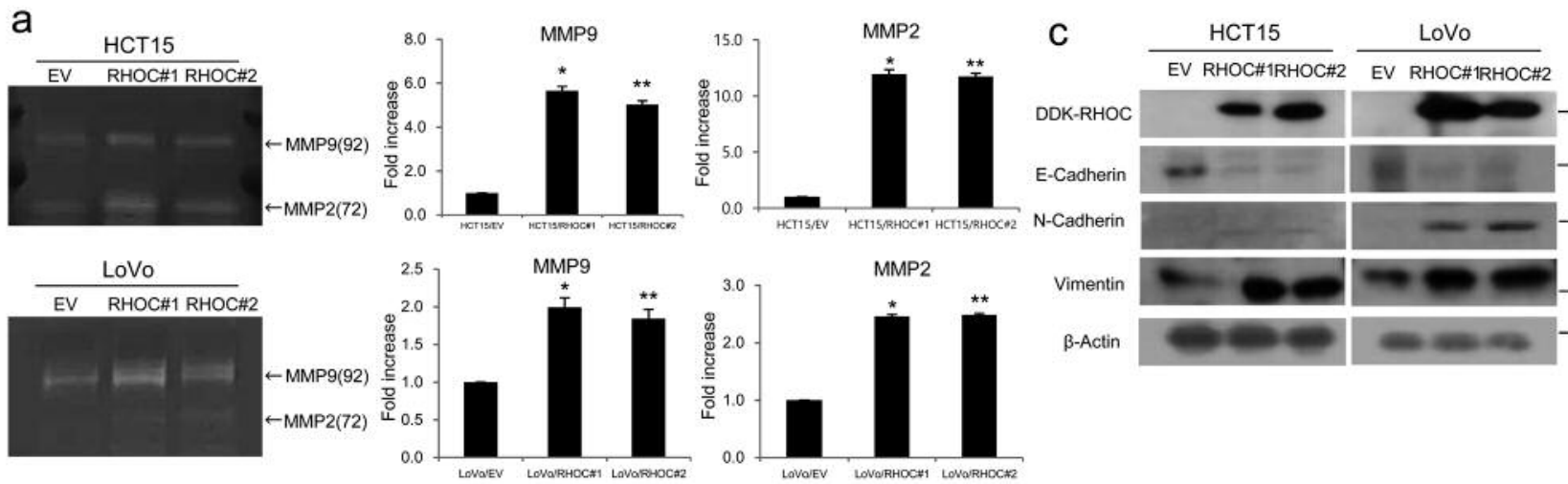

Vimentin

$\beta$-Actin
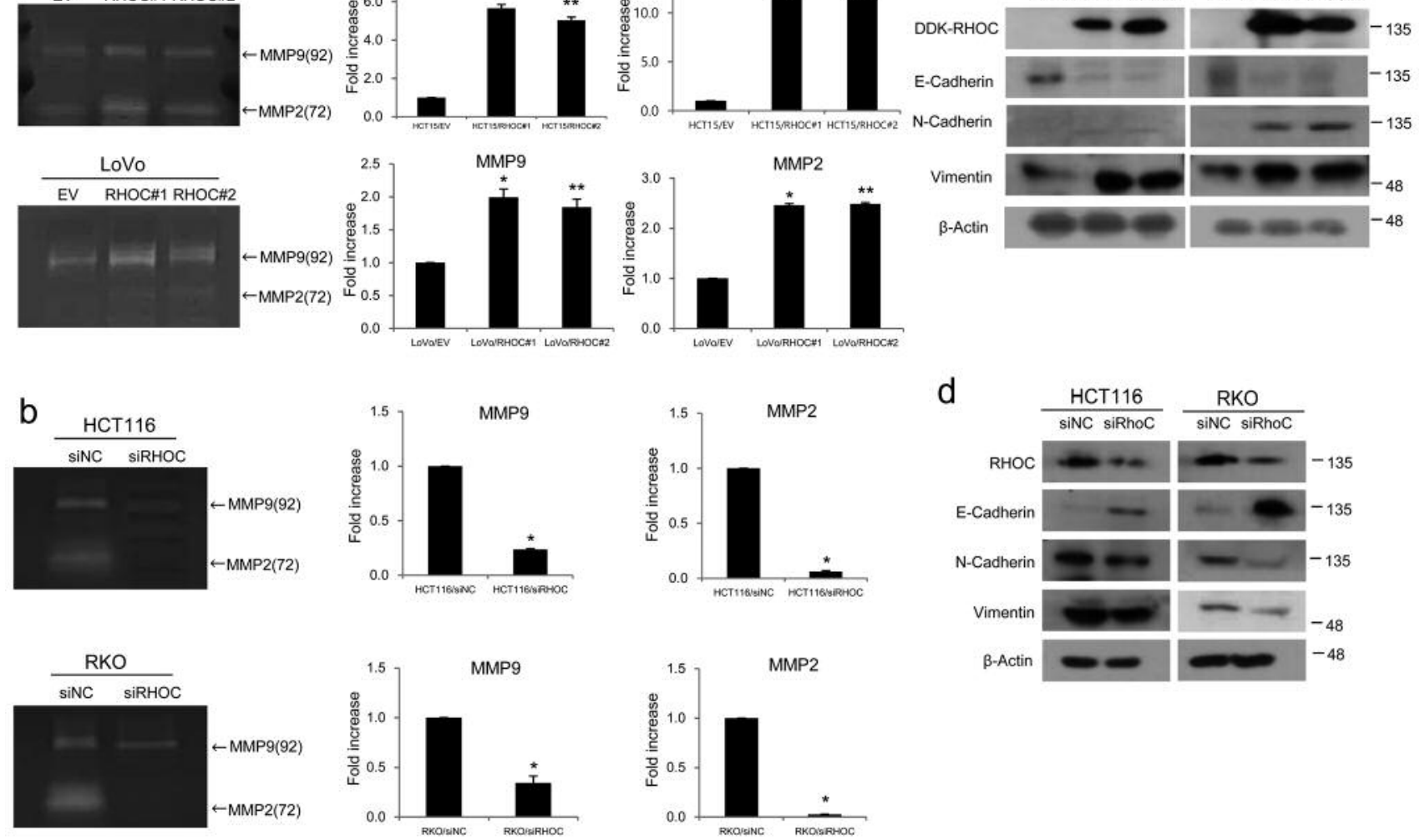

Figure 8. MMP-2 and MMP-9 activities in RHOC overexpressing (a) and RHOC knockdown (b) CRC cells, as measured by gelatin zymography after serum starvation for $24 \mathrm{~h}$. Immunoblotting of epithelial-mesenchymal transition (EMT) markers in RHOC overexpressing (c) and RHOC knockdown $(d)$ cells. Data were obtained from three independent experiments performed in triplicate. Error bars represent standard error. $* p<0.05$ between RHOC clone 1(\#1) and EV; **p<0.05 between RHOC clone 2(\#2) and EV in the overexpression study. EV, Empty vector. *p<0.05 between siRNA and siRHOC in the knockdown study. siNC: Negative control siRNA.

\section{References}

1 Wang W, Deng J, Wang Q, Yao Q, Chen W, Tan Y, Ge Z, Zhou $\mathrm{J}$ and Zhou Y: Synergistic role of Cul1 and c-Myc: Prognostic and predictive biomarkers in colorectal cancer. Oncol Rep 38(1): 245-252, 2017. PMID: 28560438. DOI: 10.3892/or.2017.5671

2 Favoriti P, Carbone G, Greco M, Pirozzi F, Pirozzi RE and Corcione F: Worldwide burden of colorectal cancer: a review. Updates in Surgery 68(1): 7-11, 2016. PMID: 27067591. DOI: 10.1007/s13304-016-0359-y

3 Boussios S, Ozturk MA, Moschetta M, Karathanasi A, Zakynthinakis-Kyriakou N, Katsanos KH, Christodoulou DK and Pavlidis N: The developing story of predictive biomarkers in colorectal cancer. J Pers Med 9(1), 2019. PMID: 30736475. DOI: $10.3390 /$ jpm 9010012

4 Carlsson U, Lasson A and Ekelund G: Recurrence rates after curative surgery for rectal carcinoma, with special reference to their accuracy. Dis Colon Rectum 30(6): 431-434, 1987. PMID: 3595361.

5 Midgley R and Kerr D: Colorectal cancer. Lancet 353(9150): 391-399, 1999. PMID: 9950460. DOI: 10.1016/s0140-6736(98) 07127-x
6 Varghese A: Chemotherapy for stage II colon cancer. Clin Colon Rectal Surg 28(4): 256-261, 2015. PMID: 26648796. DOI: $10.1055 / \mathrm{s}-0035-1564430$

7 Kim JC, Ha YJ, Tak KH, Roh SA, Kwon YH, Kim CW, Yoon YS, Lee JL, Park Y, Kim SK, Kim SY, Cho DH and Kim YS: Opposite functions of GSN and OAS2 on colorectal cancer metastasis, mediating perineural and lymphovascular invasion, respectively. PLoS One 13(8): e0202856, 2018. PMID: 3014 8861. DOI: 10.1371 /journal.pone.0202856

8 Chen S, Wu DD, Sang XB, Wang LL, Zong ZH, Sun KX, Liu BL and Zhao Y: The IncRNA HULC functions as an oncogene by targeting ATG7 and ITGB1 in epithelial ovarian carcinoma. Cell Death Dis 8(10): e3118, 2017. PMID: 29022892. DOI: 10.1038/cddis.2017.486

9 Wu DD, Chen X, Sun KX, Wang LL, Chen S and Zhao Y: Role of the lncRNA ABHD11-AS1 in the tumorigenesis and progression of epithelial ovarian cancer through targeted regulation of RhoC. Mol Cancer 16(1): 138, 2017. PMID: 28818073. DOI: $10.1186 / \mathrm{s} 12943-017-0709-5$

10 Wang CJ, Lai CH, Huang HJ, Hong JH, Chou HH, Huang KG and Lin JD: Recurrent cervical carcinoma after primary radical 

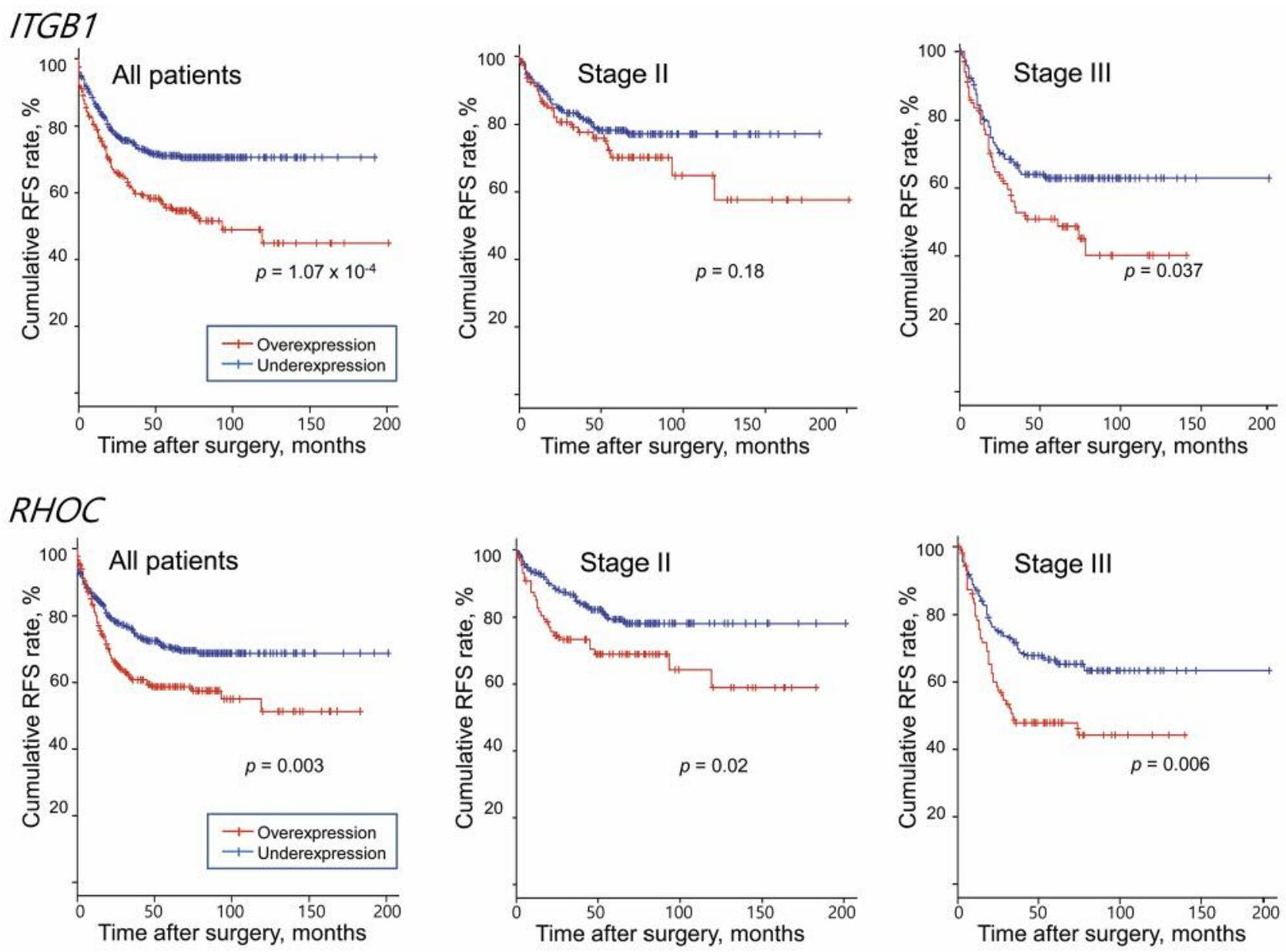

Figure 9. Recurrence-free survival (RFS) was compared between ITGB1 and RHOC mRNA-overexpressing and ITGB1 and RHOC mRNA underexpressing tumors in the CIT cohort (GSE39582, $n=566)$.

surgery. Am J Obstet Gynecol 181(3): 518-524, 1999. PMID: 10486457.

11 Graham JS and Cassidy J: Adjuvant therapy in colon cancer. Expert Rev Anticancer Ther 12(1): 99-109, 2012. PMID: 22149436. DOI: 10.1586/era.11.189

12 Carethers JM: Systemic treatment of advanced colorectal cancer: tailoring therapy to the tumor. Therap Adv Gastroenterol 1(1): 3342, 2008. PMID: 21180512. DOI: 10.1177/1756283x08093607

13 Andre T, Boni C, Mounedji-Boudiaf L, Navarro M, Tabernero J, Hickish T, Topham C, Zaninelli M, Clingan P, Bridgewater J, Tabah-Fisch I and de Gramont A: Oxaliplatin, fluorouracil, and leucovorin as adjuvant treatment for colon cancer. N Engl J Med 350(23): 2343-2351, 2004. PMID: 15175436. DOI: 10.1056/NEJ Moa032709

14 Kuebler JP, Wieand HS, O'Connell MJ, Smith RE, Colangelo LH, Yothers G, Petrelli NJ, Findlay MP, Seay TE, Atkins JN, Zapas JL, Goodwin JW, Fehrenbacher L, Ramanathan RK, Conley BA, Flynn PJ, Soori G, Colman LK, Levine EA, Lanier KS and Wolmark N: Oxaliplatin combined with weekly bolus fluorouracil and leucovorin as surgical adjuvant chemotherapy for stage II and III colon cancer: results from NSABP C-07. J
Clin Oncol 25(16): 2198-2204, 2007. PMID: 17470851. DOI: $10.1200 /$ jco.2006.08.2974

15 Sun Q, Zhou C, Ma R, Guo Q, Huang H, Hao J, Liu H, Shi R and Liu B: Prognostic value of increased integrin-beta 1 expression in solid cancers: a meta-analysis. Onco Targets Ther 11: 1787-1799, 2018. PMID: 29636624. DOI: $10.2147 /$ ott.S155279

16 Damiano JS: Integrins as novel drug targets for overcoming innate drug resistance. Curr Cancer Drug Targets 2(1): 37-43, 2002. PMID: 12188919.

17 Cordes $\mathrm{N}$ and Beinke C: Fibronectin alters cell survival and intracellular signaling of confluent A549 cultures after irradiation. Cancer Biol Ther 3(1): 47-53, 2004. PMID: 14726672.

18 Huang C, Park CC, Hilsenbeck SG, Ward R, Rimawi MF, Wang YC, Shou J, Bissell MJ, Osborne CK and Schiff R: beta1 integrin mediates an alternative survival pathway in breast cancer cells resistant to lapatinib. Breast Cancer Res 13(4): R84, 2011. PMID: 21884573. DOI: $10.1186 /$ bcr2936

19 Guo L, Zhang F, Cai Y and Liu T: Expression profiling of integrins in lung cancer cells. Pathol Res Pract 205(12): 847853, 2009. PMID: 19674850. DOI: 10.1016/j.prp.2009.07.005 
20 Zheng W, Jiang C and Li R: Integrin and gene network analysis reveals that ITGA5 and ITGB1 are prognostic in non-small-cell lung cancer. Onco Targets Ther 9: 2317-2327, 2016. PMID: 27143927. DOI: $10.2147 /$ ott.S91796

21 Zhao L, Wang H, Li J, Liu Y and Ding Y: Overexpression of Rho GDP-dissociation inhibitor alpha is associated with tumor progression and poor prognosis of colorectal cancer. J Proteome Res 7(9): 3994-4003, 2008. PMID: 18651761. DOI: 10.1021/ pr800271b

22 Morris SW, Valentine MB, Kirstein MN and Huebner K: Reassignment of the human ARH9 RAS-related gene to chromosome 1p13-p21. Genomics 15(3): 677-679, 1993. PMID: 8468062. DOI: $10.1006 /$ geno.1993.1124

23 Iwaki N, Karatsu K and Miyamoto M: Role of guanine nucleotide exchange factors for Rho family GTPases in the regulation of cell morphology and actin cytoskeleton in fission yeast. Biochem Biophys Res Commun 312(2): 414-420, 2003. PMID: 14637153.

24 Durkin ME, Avner MR, Huh CG, Yuan BZ, Thorgeirsson SS and Popescu NC: DLC-1, a Rho GTPase-activating protein with tumor suppressor function, is essential for embryonic development. FEBS Lett 579(5): 1191-1196, 2005. PMID: 15710412. DOI: $10.1016 /$ j.febslet.2004.12.090
25 Kase S, Sugio K, Yamazaki K, Okamoto T, Yano $\mathrm{T}$ and Sugimachi K: Expression of E-cadherin and beta-catenin in human non-small cell lung cancer and the clinical significance. Clin Cancer Res 6(12): 4789-4796, 2000. PMID: 11156236.

26 Yuan X, Sun X, Shi X, Wang H, Wu G, Jiang C, Yu D, Zhang W, Xue B and Ding Y: USP39 promotes colorectal cancer growth and metastasis through the $\mathrm{Wnt} /$ beta-catenin pathway. Oncol Rep 37(4): 2398-2404, 2017. PMID: 28259917. DOI: 10.3892/or.2017.5454

27 Rashed HE, Hussein S, Mosaad H, Abdelwahab MM, Abdelhamid MI, Mohamed SY, Mohamed AM and Fayed A: Prognostic significance of the genetic and the immunohistochemical expression of epithelial-mesenchymalrelated markers in colon cancer. Cancer Biomark 20(1): 107-122, 2017. PMID: 28759954. DOI: $10.3233 / \mathrm{cbm}-170034$
Received August 5, 2019

Revised August 6, 2019

Accepted August 7, 2019 